\title{
Formation of Starch in Storage Organs II
}

\author{
The Starch Formation in Maize Kernel*
}

\author{
By Shichiro HoRI**
}

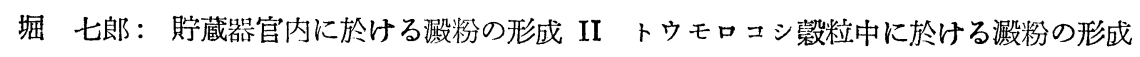

\section{Received September 9, 1954}

In a previous paper a histochemical investigation on the distribution of phosphorylase in potato tuber and the formation of storage starch therein was briefly reported (Hori, 1954). In extending the study to the starch seeds experiments were conducted on the starch formation in the maize kernel.

Phosphorylase in maize kernel has been investigated quantitatively by Nakamura and Toda (1951) who found the presence of a considerable amount of this enzyme, but no histochemical studies have so far been available on the distribution and activity of it.

The present communication describes the results of the experiments on the histological distribution of phosphorylase and the formation of starch from several kinds of sugars.

\section{Materials and Methods}

In the immature maize kernel storage starch was found mainly in the pericarp and scarcely in the nucellus, endosperm and embryo; but with the progress of maturation storage starch became filled in the endosperm and embryo in considerable amount but very little in the pericarp. It was found very difficult to remove the storage starch from the fully matured kernel, but not so from the less matured. All the samples employed in this experiment were taken from the immature kernels such as shown in Figs. 2-4. Among various procedures tried to remove the storage starch, the following was found to be the most successful.

The ears with the husks were cut off from the plant and kept in the dark with the cut shank immersed in distilled water. The storage starch in the kernel could be removed within 1 or 2 weeks, the duration differring with their ripeness degrees. In the endosperm cells of the immature kernel from which the storage starch had been completely removed, many amyloplasts were found around the nucleus and close to the cell wall (Fig. 5).

\footnotetext{
* The writer wishes to express his sincere appreciation for the valuable suggestions and criticism received from Professor T. Miwa, Botanical Institute, Tokyo University of Education, where this study was made.

** Biological Institute of Kushiro Branch, Hokkaido Gakugei University 北海道学芸大学釧路分校生物学研究室
} 
For examining the histological distribution of phosphorylase, free hand sections from starch-free kernels were incubated in a 0.5 per cent Cori-ester solution, buffered at $\mathrm{pH} 6.0$ with sodium acetate. After keeping them in the dark for 24 hours at $20^{\circ} \sim 25^{\circ} \mathrm{C}$., they were examined under microscope, staining with iodine. The quantity of phosphorylase within the cells was roughly estimated by the amount of starch produced from Cori-ester.

The starch formation from sugars was tested as follows. The kernels which had been freed of storage starch were plucked off from the cob and immersed in various kinds of the sugar solution. After keeping them in the dark for several days, the sections from them were examined for the starch formation with iodine.

\section{Results}

1) Distribution of Phosphorylase

The histological distribution of phosphorylase in the maize kernel is shown in Fig. 1.

As shown in Fig. 1, phosphorylase was found abundantly in the endosperm and

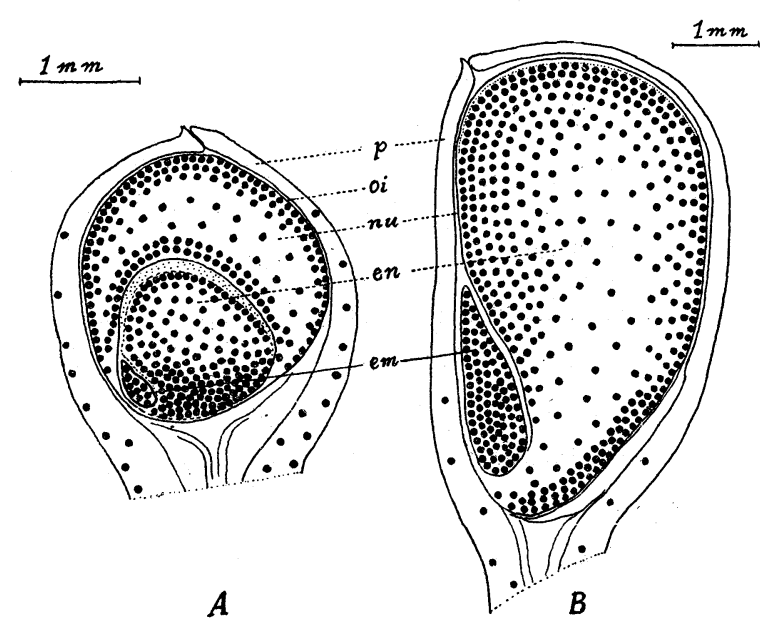

Fig. 1. Diagrammatical illustration of the histological distribution of phosphorylase in the maize kernel. Both of the figures, $\mathrm{A}$ and $\mathrm{B}$, are the median longitudinal sections cut at right angles to the flat surfaces of the kernel. Density of dots indicates the relative intensity of phosphorylase reaction with Cori-ester.

p, pericarp; oi, seed coat; nu, nucellus; en, endosperm; em, embryo; A. immature kernel; B, nearly matured kernel.

were small granules or branched chains of granules stainable violet with iodine spreading into the cytoplasm (Figs. 9, 10).

2) Starch Formation from Sugars

When the kernel was immersed in various kinds of the sugar solution for more and within the endosperm it was richest at the base. The enzyme content in the endosperm of the immature seed was large as compared with that of the matured. The enzyme was also found in the nucellus when the kernel was very young, especially close to the endosperm and at the upper periphery. It was further detected in the sieve tubes but not in the vessels.

The products from Cori-ester in the endosperm cells were grains stainable violet with iodine, as. sembling around the nucleus, so that they appeared in form of spherical group of violet grains in the midst of each cell (Fig. 8). The products in the nucellar cells embryo but little in the pericarp ; 
than 5 days, starch grains were produced within the endosperm cells. The formation of starch was little affected by whether the kernels had been kept floating on or immersed in the sugar solution. The starch grains thus formed showed the same appearance as the natural storage starch, stainable violet blue with iodine and crowded around the nucleus, appearing in form of large spherical mass in the midst of each cell. They were supposed to be derived from the amyloplasts which were found around the nucleus (Figs. 6, 7).

The formation of starch in various kinds of sugar solutions is given in Table I.

Table I. Formation of starch in the endosperm cells of the maize kernel in various kinds of sugar solutions

\begin{tabular}{|c|c|c|c|}
\hline Sugar supplied & $\begin{array}{c}\text { Concentration of sugar } \\
\text { solution } \%\end{array}$ & $\begin{array}{c}\text { Incubation time } \\
\text { day }\end{array}$ & Starch test \\
\hline Sucrose & 10 & $\begin{array}{l}5 \\
7\end{array}$ & $\stackrel{+}{+}$ \\
\hline Maltose & $"$ & $\begin{array}{l}5 \\
7\end{array}$ & $\begin{array}{c}+ \\
\text { decay }\end{array}$ \\
\hline Glucose & $"$ & $\begin{array}{l}5 \\
7\end{array}$ & H \\
\hline Fructose & $"$ & $\begin{array}{l}5 \\
7\end{array}$ & H \\
\hline Galactose & $"$ & $\begin{array}{l}5 \\
7\end{array}$ & $\stackrel{+}{\text { decay }}$ \\
\hline Sucrose & 15 & $\begin{array}{l}5 \\
7\end{array}$ & $\begin{array}{c}\text { plasmolysis } \\
\text { death }\end{array}$ \\
\hline$"$ & 5 & $\begin{array}{l}5 \\
7\end{array}$ & \# \\
\hline$"$ & 1 & $\begin{array}{l}5 \\
7\end{array}$ & $\overline{-}$ \\
\hline
\end{tabular}

Temperature, $20^{\circ} \sim 25^{\circ} \mathrm{C}$; - , no starch formation; + , trace; $H$, intermediate; $\#$, abundant.

The starch formation required at laest five days of incubation under these conditions. Sucrose, glucose and fructose were the most favourable for the starch formation, while maltose and galactose formed starch but little for five days of incubation. In these sugar solutions the kernels decayed after seven days. The higher concentration of the sugar solution caused plasmolysis and no starch was formed while the too low concentration was ineffective for the starch formation.

\section{Discussion}

In the maize kernel, phosphorylase was found mainly in the tissues containing storage starch, such as endosperm and embryo, but as well as in the tissues devoid of storage starch, such as sieve tubes and nucellus. These features represent a striking resemblance to those in potato tuber as previously reported (Hori, 1954). Hence it may be suggested that this enzyme not only plays an important role in the starch formation in storage organs but also has some relation to the translocation of a carbohydrates in sieve tubes. 
The products from Cori-ester in the maize kernal differ most remarkably from those in potato tuber in form and iodine colour, that is, in the former the colour is violet and the form is granular or branched chains as compared with the latter, whose products are pure blue with iodine and only granular. In the endosperm they are produced in the amyloplasts around the nucleus in closely similar manner as the starch formation from sugar. From this, it seems quite possible that phosphorylase is contained in the amylopasts from which either starch grains or the products from Cori-ester arose. This fact seems to confirm the findings of Yin (1948) that phosphorylase is located exclusively in the plastids.

On the other hand, Stocking (1952) reported that polysaccharide synthesis occurred equally outside the plastids of starch-free leaf cells by the action of phosphorylase upon Cori-ester. The writer also showed in the present experiment the formation from Cori-ester of starch like substances in nucellar cells and sieve tubes, both of which usually lack plastids and starch grains. In potato tubers similar phenomena were also observed (Hori, 1954). These findings are obviously inconsistent with the statement of Yin $(1948,1949)$ that phosphorylase is not detectable in those plant tissues where no starch grains are formed and that the presence of this enzyme is rather intimately associated with plastids. Accordingly further investigations seem to be needed for the solution of the problem as to whether or not phosphorylase is really localized exclusively in plastids.

\section{Summary}

1. The histological distribution of phosphorylase in the maize kernel and the starch formation therein were investigated.

2. In the mature kernel phosphorylase was found mainly in the endosperm and embryo, especially abundant at the base of the former. In the immature kernel in which the endosperm and embryo had not yet fully developed, the enzyme was detected mainly in the nucellus, and when very young, also in the pericarp.

3. The products from Cori-ester in the endosperm were grains stainable violet with iodine, arising from the amyloplasts around the nucleus, while the products in the nucellus were small granules or branched chains of granules stainable similarly as those in the endosperm, dispersing throughout the cytoplasm of the cell.

4. By supplying each of the following sugars through the kernel stalk, starch grains were formed in the cells of the endosperm: sucrose, maltose, glucose, fructose and galactose; among them, sucrose, glucose and fructose were found to be the most favourable. Under these circumstances the starch formation occurred in the amyloplasts which were located chiefly around the nucleus.

\section{Literature}

1. Von Ohlen, F. W. Amer. Jour. Bot. 18: 30-42 (1931)

2. Sharp, L. W. Introduction to Cytology. 65 (1934) 
3. Hanes, C. S. Proc. Roy. Soc. 129 : 174-208 (1940)

4. Yin, H. C. \& Sun, C. N. Science $105: 650$ (1947)

5. _ \& Tung, Y. T. Science 108: 87-88 (1948)

6. - Nature 162: 928-929 (1948)

7. . \& Sun, C. N. Plant Physiol. $24: 103-110$ (1949)

8. Dyar, M. T. Amer. Jour. Bot. 37 : 786-791 (1950)

9. Curtis, O. F. \& Clark, D. G. Introduction to Plant Physiology. 218-219 (1950)

10. Nakamura, M. \& Maruo, B. J. Agr. Soc. Jap. 25 (5): 245-248 (1951)

11. _ \& Yamazaki, K. J. Agr. Soc. Jap. 24 (5): 197-201 (1951)

12. —. J. Agr. Soc. Jap. 24 (7): 299-302 (1951)

13. - J. Agr. Soc. Jap. 24 (7): 302-309 (1951)

14. . \& Toda, H. J. Agr. Soc. Jap. 25 (5): 248-252 (1951)

15. Baba, A., Shimabayashi, Y. \& Iwamoto, K. J. Agr. Soc. Jap. 25 (5) : 252-254 (1951)

16. Siegel, S. M. Dynamic Aspects of Biochemistry. 2nd edition. 129-133 (1952)

17. Stocking, C. R. Amer. Jour. Bot. 39 : 283-287 (1952)

18. Ono, H. Bot. Mag. Tokyo 66: 777-778 (1953)

19. —. Bot. Mag. Tokyo 66 : 781-782 (1953)

21. Nakamura, M. Nature 171: 795-796 (1953)

21. Sumner, J. B. \& Somers, G.F. Chemistry and Methods of Enzymes. 321-358 (1953)

22. Hori, S. Bot. Mag. Tokyo 67 : 789-790 (1954)

\section{Explanation of Plate}

Figs. 2-4. Median longitudinal sections cut at right angles to the flat surfaces of the kernel, showing the various developmental stages. Fig. 2, youngest; Fig. 4, most developed; p, pericarp; nu, nucellus; en, endosperm; em, embryo. All $\times 14$.

Fig. 5. Starch-free endosperm cells of the same section as in Fig. 3, showing the amyloplasts around the nucleus and close to the cell wall. $\times 200$.

Figs. 6, 7. Longitudinal sections of the endosperms of the kernels, showing the starch grains formed from sucrose; representing spherical groups around the nuclei, stained with iodine. Fig. 6, section from an immature kernel as in Fig. 3; Fig. 7, section from a further developed kernel as in Fig. 4. Both $\times 50$.

Fig. 8. Magnified view of a portion of the endosperm shown in Fig. 3, showing the products from Cori-ester, in form of spherical masses around the nuclei, stained with iodine. $\times 50$.

Figs. 9, 10. Magnified views of the portions of the nucellus shown in Fig. 3, showing the products from Cori.ester. Fig. 9, prducts in form of small granules; Fig. 10, products in form of branched chains of granules. Both $\times 200$. 

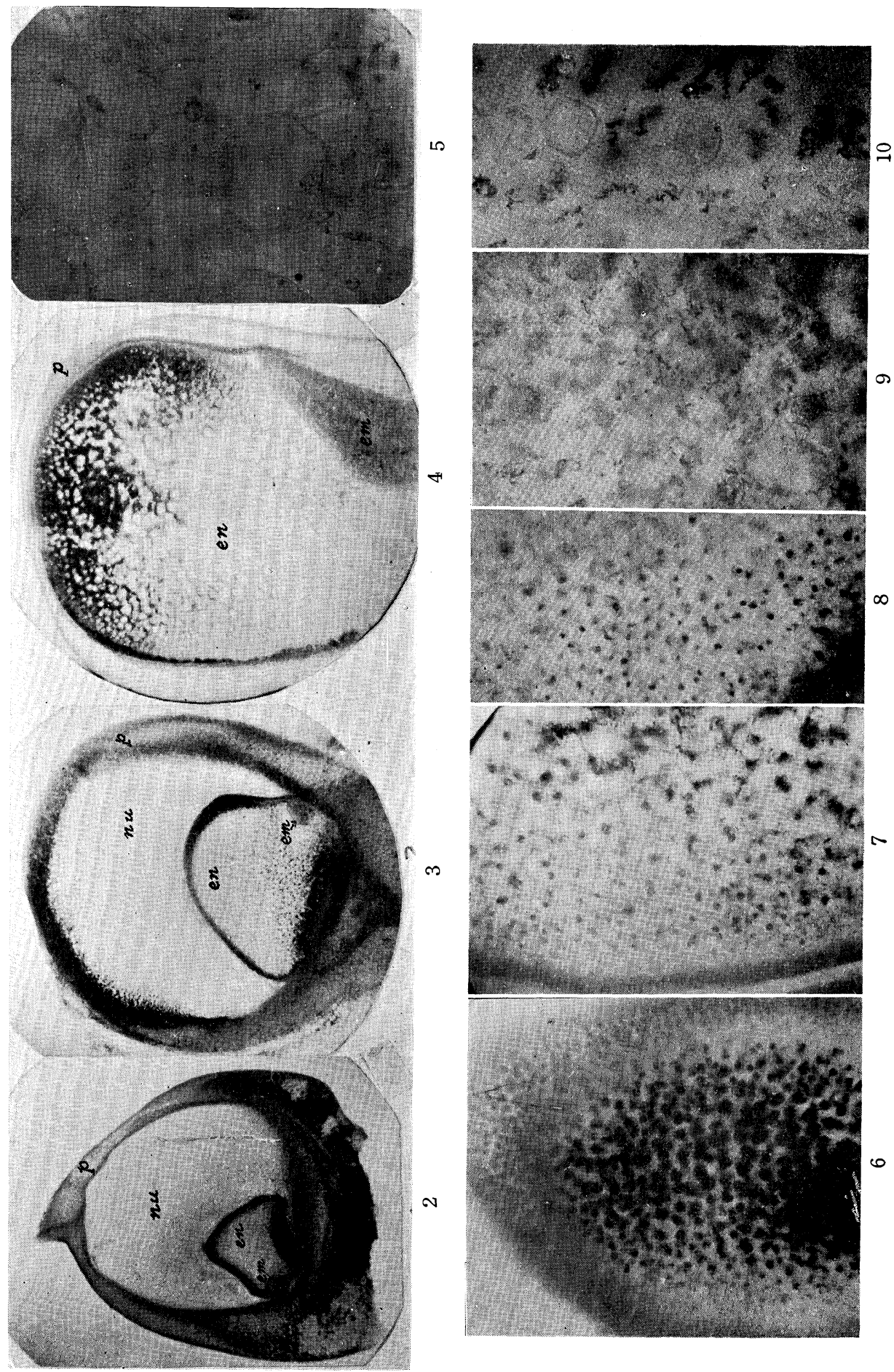

\section{S. Hori :}

